\title{
Análise do potencial e da demanda de visitação da Floresta Nacional de Capão Bonito (SP)
}

\section{Analysis of the potential and demand for visitation in Capão Bonito National Forest (SP, Brazil)}

\author{
Mariane Thais Santos, Ismail Barra Nova de Melo, Eliana Cardoso-Leite
}

\begin{abstract}
RESUMO: As Florestas Nacionais tem como objetivo o uso múltiplo dos recursos florestais, pesquisa científica com ênfase em métodos para a exploração sustentável de florestas e permitem a visitação pública. Este estudo teve como objetivo analisar o potencial de Uso Público da Floresta Nacional de Capão Bonito e a existência de demanda por visitação das comunidades do entorno. Como procedimentos metodológicos foram realizadas entrevistas com uma parcela população dos municípios de Capão Bonito e Buri e com a gestora da Flona. Foi também analisada a presença de atrativos turísticos e de infraestrutura necessária para atividades de uso público. Os resultados mostraram que a maioria dos entrevistados, desconhecia até então as estratégias de conservação ambiental e nunca havia visitado a Flona, porém apresentou interesse em visitá-la. A gestão da Flona avaliou que a mesma tem potencial para visitação, porém registrou que esta atividade só deveria acontecer com a publicação do Plano de Manejo da Unidade. Os resultados mostraram também que a Flona de Capão Bonito apresenta atrativos e possui muitos dos itens de infraestrutura considerados mínimos para viabilização de seu Uso Público. Conclui-se que a Floresta Nacional tem potencial de Uso público como patrimônio natural e histórico/cultural e apresenta demanda de visitantes dos municípios do entorno.
\end{abstract}

PALAVRAS-CHAVE: Ecoturismo; Floresta Nacional; Uso Público.

ABSTRACT: The National Forests ("Flona") aims at multiple use of forest resources, scientific research with emphasis on methods for the sustainable exploitation of forests and permit public visitation. This study aimed to analyze the potential of Public Use of the Capão Bonito National Forest and the existence of demand for visitation of the surrounding communities. As methodological procedures were carried out interviews with a population sample from Capão Bonito and Buri cities and with the Flona's manager. It also analyzed the presence of tourist attractions and infrastructure necessary for public use activities. The results showed that most of the interviewees were previously unaware of environmental conservation strategies and had never visited Flona, but they had shown interest in visiting it. Flona's manager evaluated that it has potential for visitation but noted that this activity should only happen after the publication of the Management Plan of the Unit. The results also showed that the Capão Bonito National Forest de presents attractive and has many of the items of infrastructure considered minimum to enable its Public Use. It is concluded that the National Forest has potential of Public use as natural and historical /cultural patrimony and presents demand of visitors from surrounding municipalities.

KEYWORDS: Ecotourism; National Forest; Public Use. 


\section{Introdução}

Ao longo do tempo áreas naturais foram destruídas alterando a paisagem natural e, consequentemente, o hábitat de diversas espécies. Com as políticas ambientais, surgiram modelos de proteção natural. A criação de Áreas Protegidas representa a estratégia de conservação mais utilizada no mundo, sendo que estas são áreas naturais com limites geográficos definidos e reconhecidos. O objetivo da criação de Áreas Protegidas está pautado na proteção e conservação ambiental de paisagens naturais, assim como aspectos culturais, relacionados à área natural (BRASIL, 2016).

Em âmbito internacional, destaca-se a União Internacional para a Conservação da Natureza (IUCN, 1994). De acordo com os diferentes objetivos estabelecidos pela IUCN, as Áreas Protegidas estão dispostas em seis diferentes categorias: Categoria I: Reserva Natural Estrita/Área Selvagem (objetivo de uso científico e preservação da natureza); Categoria II: Parque Nacional (voltado para a educação ambiental e preservação da natureza); Categoria III: Monumento Natural (objetivo de conservação de áreas naturais específicas classificadas como cânions, cachoeiras e outras); Categoria IV: Área de Manejo de Espécies (objetivo a conservação com ênfase no manejo); Categoria V: Paisagem Protegida (conservação de paisagens terrestres e marinhas); Categoria VI: Área Protegida de Recursos Manejados (objetivo de uso sustentável dos recursos naturais).

O Parque Nacional (PN) de Yellowstone foi o primeiro modelo de Área Protegida a ser criado no mundo em 1872, trazendo consigo o objetivo de conservação de um uma paisagem de beleza cênica no qual o parque estava inserido. Bensusan e Prates (2014) comentam que no ato de criação do PN Yellowstone o congresso nacional dos Estados Unidos determinou que a região fosse reservada e proibida de ser colonizada, ocupada ou vendida, e que o ser humano ali deveria ser um visitante e nunca um morador. Este modelo foi adotado por muitos outros países do mundo e, em vários deles, vigora até os nossos dias (BENSUSAN; PRATES, 2014).

No Brasil uma das estratégias para proteção da Natureza é a criação de Unidades de Conservação (UCs). Estas UCs são regulamentadas pelo Sistema Nacional de Unidades de Conservação (BRASIL, 2000) e tem como definição: "[...] espaço territorial e seus recursos ambientais, incluindo as águas jurisdicionais, com características naturais relevantes, legalmente instituído pelo Poder Público, com objetivos de conservação e limites definidos, sob regime especial de administração, ao qual se aplicam garantias adequadas de proteção". O SNUC divide as UCs em dois principais grupos: Grupo I: Unidades de Conservação de Proteção Integral (UCPI) que tem por finalidade o uso indireto dos recursos naturais em relação à proteção da natureza e tem como norma a proibição de qualquer população residente no local, é subdividida em 5 categorias: Estação Ecológica, Reserva Biológica, Parque Nacional, Monumento Natural e Refúgio de vida Silvestre; Grupo II: Unidades de Conservação de Uso Sustentável (UCUS) busca a proteção ambiental e o uso sustentável dos recursos naturais, é subdividida em 7 categorias: Área de Proteção 
Ambiental (APA), Área de Relevante Interesse Ecológico, Floresta Nacional, Reserva Extrativista, Reserva de Fauna, Reserva de Desenvolvimento Sustentável e Reserva Particular do Patrimônio Natural (BRASIL, 2000).

Estas áreas protegidas ou Unidades de Conservação, também fomentam a pesquisa científica e protegem as comunidades tradicionais e 0 patrimônio histórico/cultural relacionados à Unidade de Conservação, especialmente nas categorias Reserva Extrativista e Reserva de Desenvolvimento Sustentável (BRASIL, 2000).

As UCs distribuídas pelo país abrangem os diferentes biomas presentes no território brasileiro (Amazônia, Caatinga, Cerrado, Mata Atlântica, Pampa e Pantanal). O Bioma Mata Atlântica (bioma onde está inserida a UC foco deste estudo) encontra-se altamente ameaçado, pois sofreu alterações em sua estrutura e composição, devido a pressão antrópica historicamente exercida sobre o mesmo ao longo do processo de colonização, expansão da fronteira agrícola e urbanização.

O Bioma Mata Atlântica é composto por diferentes fitofisionomias (ou ecossistemas): Floresta Ombrófila Aberta, Floresta Ombrófila Mista, Floresta Estacional Semidecidual, Floresta Estacional Decidual, Mangues e Restingas (IBGE, 2012). Mesmo com a intensa degradação desse Bioma, que se iniciou no período colonial com a extração de madeiras para a produção de móveis e carvão, seguida pela expansão da agricultura e extração de minérios de suas áreas naturais, a Mata Atlântica continua abrigando em seu território uma das maiores biodiversidades do Planeta. Possui aproximadamente 2.300 espécies de vertebrados (aproximadamente 740 espécies endêmicas) e 20 mil espécies de plantas vasculares (aproximadamente 8 mil espécies endêmicas) (MYERS et al., 2000; MITTERMEIER et al., 2004). Devido à sua importância ambiental e ao seu alto grau de pressão de destruição, a Mata Atlântica também é considerada um hotspot mundial e tem prioridade de conservação junto a outras 34 regiões do mundo (LAURANCE, 2009).

A visitação pública é garantida para a maioria das categorias de UC previstas no SNUC, como é o caso dos Parques Nacionais ou Estaduais, Florestas Nacionais e outras categorias. De acordo com o SNUC a categoria Floresta Nacional (FLONA) inserida no grupo de Unidades de Conservação de Uso Sustentável (UCUS) tem como objetivo o uso sustentável de recursos florestais, o fomento à pesquisa científica (priorizando métodos de exploração sustentável de florestas nativas) permitindo também o uso público. Esta atividade pode ser desenvolvida desde que estejam de acordo com as normas e diretrizes previamente estabelecidas no Plano de Manejo da Unidade (BRASIL, 2000).

Segundo o Roteiro Metodológico para Elaboração de Planos de Manejo (PM) de Flonas (ICMBIO, 2009), dentro do PM deve existir um "Programa de Uso Público" cujo objetivo é ordenar, orientar e direcionar o uso da área pelo visitante, promovendo seu contato com a Natureza por meio de lazer, recreação e ecoturismo, mas de acordo com as potencialidades da área e com a capacidade de suporte dos locais a serem visitados (ICMBIO, 2009). 
Existem estudos sobre Uso Público em Florestas Nacionais, como aqueles realizados por Dos Santos e Lima (1999); Souza e Martos (2008), Moreira e Burns (2015), Campolim, (2016) e Cruz et al. (2017).

Os trabalhos de Moreira e Burns (2015) e de Cruz (2017) foram realizados em Flonas na região norte. Dos Santos e Lima (1999) estudaram o potencial de uso público da FLONA Mário Xavier, localizada em Seropédica/RJ. Assim como a FLONA de Capão Bonito, a UC representa uma das únicas formas de relação direta do Homem com a Natureza, na região onde está inserida. Os autores (SANTOS; LIMA,1999) utilizaram um questionário semiestruturado, que foi aplicado na população do entorno, com o objetivo de definir o perfil dos possíveis visitantes da área. Foi observada a necessidade de melhorias na infraestrutura, como o aumento da segurança da área e a criação de um centro de visitantes. Em relação às atividades naturais e histórico/culturais, os autores observaram a necessidade de criação do planejamento de atividades desenvolvidas na UC, assim como a criação de áreas de lazer para os visitantes e programas de Educação Ambiental (EA). Os autores concluíram que com tais adequações tornaram possível o uso público na FLONA Mário Xavier.

Souza e Martos (2008) e Campolim (2016) estudaram aspectos do uso público na Flona de Ipanema. Campolim (2016) registrou que esta Flona é bem servida em relação à sua infraestrutura (quiosques, centro de visitantes, fácil acesso e outros) e atrativos naturais ou histórico/culturais (área de lazer, trilhas, monumentos históricos). Segundo Souza e Martos (2008) os visitantes da Flona Ipanema entrevistados em seu estudo foram majoritariamente jovens, com bom nível cultural e econômico, provindos de áreas do entorno da Flona, com expectativas de contato com a Natureza e com preocupação com a manutenção da qualidade do ambiente local.

Outros estudos sobre Uso Público em Unidades de Conservação foram realizados no sudeste do Brasil, como aqueles realizados por Malta (2009) no Parque Nacional da Tijuca/RJ, por Bueno (2011) no Parque Estadual Morro do Diabo, e por Valenti (2015) no Núcleo Picinguaba do Parque Estadual da Serra do Mar.

Diversos estudos já foram realizados na Flona de Capão Bonito. Alguns relacionadas a vegetação nativa ou exótica, como os estudos de Brassiolo (1988) e Ramos (2015). Outros autores estudaram aspectos da fauna, como Rodriguez (2015) que estudou caça legal como possibilidade de controle de uma população invasora de javali, e Caldano (2014) que estudou uma espécie de mico-leão-preto (Lontopithecus chrysopygus Mikan, 1823). Também já foram estudadas as bacias hidrográficas presentes na área (LEAL, 2016) e aspectos da paisagem utilizando indicadores de avifauna (MATOS, 2015). No entanto, inexistem estudos sobre quaisquer aspectos do Uso Público da Flona de Capão Bonito, nem sobre demandas de visitação por comunidades do entorno.

Neste estudo, parte-se do pressuposto de que as Unidades de Conservação representam locais privilegiados para realização de atividades de lazer, recreação e ecoturismo (MONZ et al. 2009) que podem, acima de tudo, promover a reconexão do ser humano com a Natureza (TUAN, 1980, 
MENDONÇA, 2007). Desta forma a experiência em visitar uma Unidade de Conservação, preferencialmente em uma Vivência com a Natureza (CORNELL, 2005), pode transformar as pessoas e produzir mudanças de comportamento duradouras (NEIMAN, 2009). No entanto, atividades de visitação podem produzir impactos nas Unidades de Conservação. Assim alguns autores apontam diferentes possibilidades para tentar minimizar estes impactos (COLE; CARLSON, 2010; SÃO PAULO, 2010).

Desta forma, o presente estudo objetiva analisar o potencial de uso público da Flona de Capão Bonito e a existência de demanda de visitação para a área.

\section{Materiais e Métodos}

\section{Área de estudo}

A Floresta Nacional de Capão Bonito, objeto de estudo desse trabalho se encontrava fechada para a visitação (até o momento da realização da pesquisa) desempenhando os outros objetivos previstos para UCs desta categoria, como o uso múltiplo sustentável dos recursos florestais e o fomento à pesquisa científica, com ênfase em métodos para exploração sustentável de florestas nativas (BRASIL, 2000). A área da FLONA teve sua paisagem modificada ao longo do tempo, devido a agricultura e silvicultura de espécies não nativas, e a presença de uma rodovia que divide a área em duas partes (MATOS, 2015).

A Floresta Nacional de Capão Bonito (Figura 1), foi criada pela Portaria 558, de 25 de outubro de 1968 (BRASIL, 1968). A UC está situada na Rodovia SP 258, km 241 entre os municípios de Capão Bonito e Buri. Sua área total é de 4.344 ha e está distribuída entre os municípios de Capão Bonito (43,39\%) e Buri (56,59\%).

A FLONA está inserida na Bacia Hidrográfica do Alto de Paranapanema. Na região Leste da UC se localiza o Rio Paranapitanga e a Oeste se localiza o Rio Apiaí-Mirim, a área de proteção abriga além destes cursos d'água outras inúmeras nascentes, córregos e açudes. A altitude da área varia entre 600 e 750 metros, com relevo suavemente ondulado e solo com característica do grupo latossolo (vermelho e vermelho-amarelo) na maior parte da área, sendo que a pluviosidade varia entre 1200 a 1400 mm/anuais (ICMBIO, 2018). A FLONA de Capão Bonito está inserida em área de remanescente florestal dos Biomas Mata Atlântica e Cerrado e apresenta em sua área os seguintes fitofisionomias florestais: Floresta Ombrófila Mista, Floresta Estacional Semidecidual e Savana ou Cerrado (BECHARA, 2006, ICMBIO, 2018).

Até o momento da coleta e análise de dados, a UC não possuía Plano de Manejo aprovado. No entanto o Plano de Manejo foi publicado no presente ano (ICMBIO, 2018). 


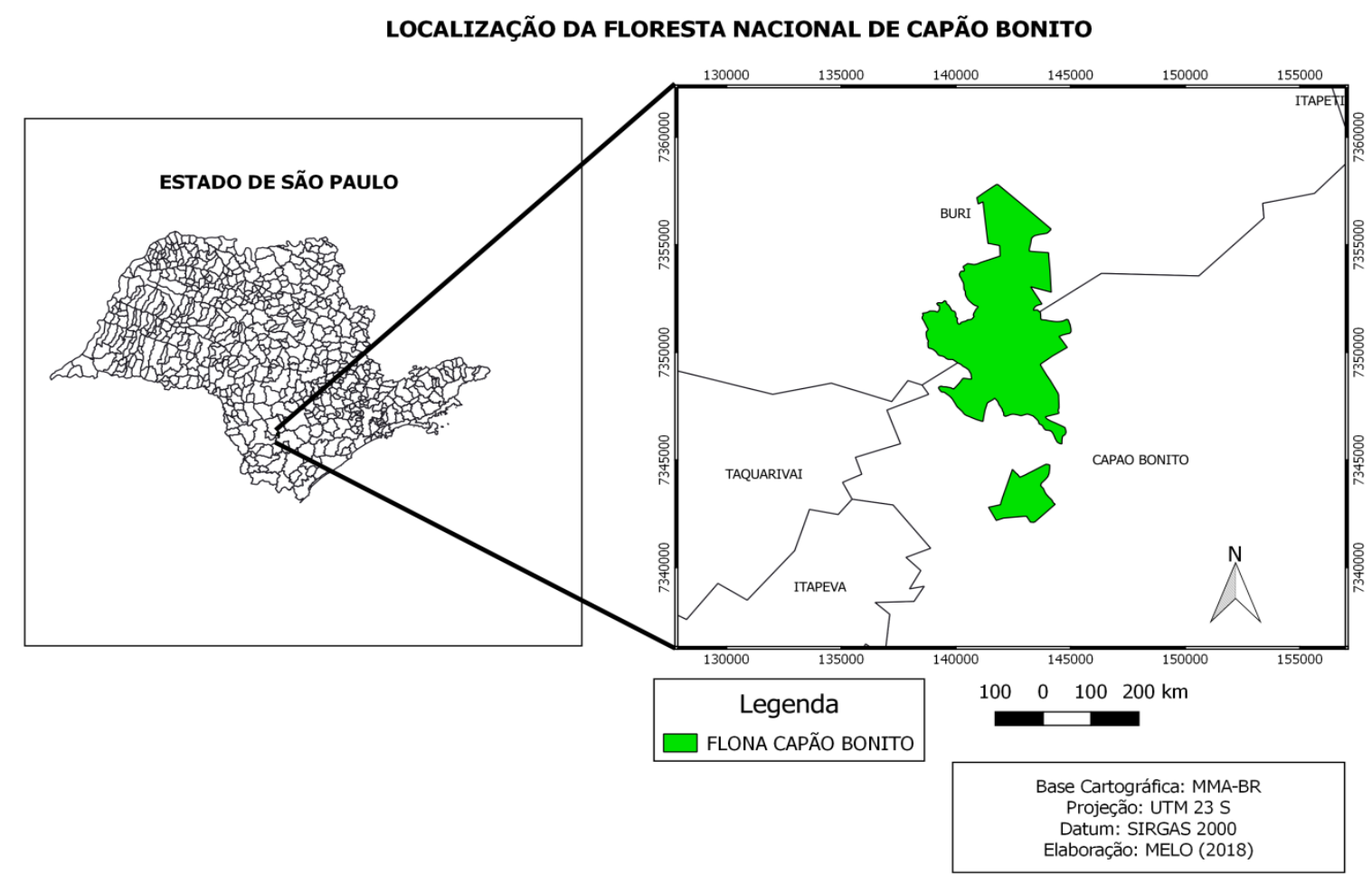

Figura 1: Localização da Floresta Nacional de Capão Bonito, no Estado de São Paulo. Figure 1: Location of Capão Bonito National Forest, inside São Paulo State.

\section{Metodologia}

A metodologia utilizada para coleta de dados foi: a- entrevista com população dos municípios envolvidos, b- entrevista com gestor(a) da UC, cPesquisa documental e análise de atrativos e de infraestrutura. A coleta de dados foi realizada entre agosto e outubro de 2017. A metodologia detalhada está apresentada a seguir.

\section{Entrevista com população dos municípios envolvidos}

Foi utilizado um roteiro para as entrevistas (Apêndice I) com uma amostra da população dos municípios de Capão Bonito e Buri para análise da demanda de visitantes para o Uso Público da FLONA de Capão Bonito. Este roteiro contou com 18 questões, sendo as questões de 1 a 10 utilizadas para caracterização dos sujeitos, e as questões de 11 a 17 para questões relacionadas ao conhecimento do que é uma Flona, e do conhecimento e interesse em visitar especificamente a Flona de Capão Bonito. A questão 18 questionou quais seriam os principais atrativos naturais que poderiam despertam o interesse dos entrevistados.

Para estabelecer o tamanho da amostra, foi utilizado o cálculo de amostra aleatória simples, de acordo com o total populacional de cada 
município, sendo considerado para o cálculo 5\% de erro amostral, 95\% de nível de confiança e 10\% de percentual máximo (BUSSAB, 2002), utilizando a fórmula:

$$
\begin{gathered}
n=\frac{N \cdot Z^{2} \cdot p \cdot(1-p)}{} \\
Z^{2} \cdot p \cdot(1-p)+e^{2} \cdot(N-1) \\
\text { Onde: } \\
\mathrm{n} \quad \text { amostra }
\end{gathered}
$$

Sendo assim, foram entrevistadas 191 pessoas ao todo, 79 no município de Capão Bonito e 112 no município de Buri.

\section{Entrevista com o(a) gestor(a)}

Foi realizada uma entrevista com o gestor(a) Unidade de Conservação. Para a entrevista foram utilizadas as seguintes questões: 1Qual a importância da FLONA de Capão Bonito para os municípios de Capão Bonito, Buri e região? 2- A FLONA de alguma maneira se relaciona com a população dos municípios do entorno? 3- Existe o Plano de Manejo para a UC? Caso não exista, ele está sendo elaborado? 4 - Em seu ponto de vista, a FLONA de Capão Bonito tem potencial para ter o uso público? Por quê? 5- Como gestor (a) você acredita que o uso público na FLONA de Capão Bonito pode trazer benefícios para a população dos municípios da região?

\section{Pesquisa documental e análise de atrativos e infraestrutura}

Uma pesquisa documental foi realizada, neste caso, com os Planos de Manejo de algumas Unidades de Conservação para servir como parâmetro de comparação com a FLONA de Capão Bonito, nos itens de infraestrutura, atrativos naturais e histórico/culturais. Foram selecionadas Unidades de Conservação inseridas na categoria "FLONA", localizadas no Estado de São Paulo (BRASIL, 2000) além de outras UCs de Proteção Integral com Uso Público consolidado (ex. Parques Nacionais ou Estaduais), localizadas em região geográfica próxima à FLONA de Capão Bonito. Diante destes critérios foram selecionadas a FLONA de Ipanema, a FLONA de Lorena e os Parques Estaduais: PE Carlos Botelho, PE Intervales, PE Caverna do Diabo, e PE Turístico do Alto Ribeira (PETAR).

Foi realizado uma listagem de itens de atrativos e de infraestrutura presentes nestas $U C$, e a partir da análise desta listagem foram 
selecionados itens mínimos que deveriam estar presentes para que a UC pudesse ser considerada apta à visitação.

Em outubro de 2017, foi realizada uma visita na Flona de Capão Bonito, na qual foi feito registro dos itens de atrativos e de infraestrutura presentes na área. Este registro foi comparado com a listagem dos atrativos e itens de infraestrutura registrados nas UCs utilizadas para comparação.

\section{Resultados e discussão}

\section{Entrevista com população dos municípios do entorno}

No total foram entrevistadas 191 pessoas, distribuídas entre os municípios de Capão Bonito e Buri, dos quais foram contabilizados 66 homens e 125 mulheres (Tabela 1). No município de Capão Bonito, os homens representaram $27 \%$ e as mulheres $73 \%$ do total de entrevistados. Já no município de Buri, os homens representam $40 \%$ e as mulheres $60 \%$ do total dos entrevistados. A idade dos entrevistados, em ambos os municípios, variou de 17 a 65 anos. A classe de idade com maior frequência relativa observada em Capão Bonito foi de 20 a 30 anos (27\%) e em Buri foi de 30 a 40 anos (20\%), como pode-se observar na Tabela 1.

Tabela 1: Caracterização dos entrevistados dos municípios de Buri e Capão Bonito, Estado de São Paulo, Brasil.

Table 1: Characterization of the interviewees from Buri and Capão Bonito municipalities, São Paulo State, Brazil.

\begin{tabular}{|c|c|c|c|c|}
\hline \multicolumn{5}{|c|}{$\mathrm{n}=191$} \\
\hline Categorias & Capão Bonito & $\begin{array}{l}\text { Total } \\
\%\end{array}$ & Buri & Total \% \\
\hline Sexo & $27 \mathrm{M} 73 \mathrm{~F}$ & 100 & $40 \mathrm{M} \quad 60 \mathrm{~F}$ & 100 \\
\hline Maior frequência de idade & 20 a 30 anos & 27 & 30 a 40 & 20 \\
\hline $\begin{array}{l}\text { Maior frequência de } \\
\text { escolaridade }\end{array}$ & Ensino Médio & 29 & Ensino Médio & 33 \\
\hline $\begin{array}{l}\text { Profissões com maiores } \\
\text { frequências }\end{array}$ & $\begin{array}{l}\text { Comerciários e } \\
\text { Estudantes (somados) }\end{array}$ & 18 & Estudantes & 20 \\
\hline Residência & Urbana & 59 & Rural & 53 \\
\hline
\end{tabular}

O nível de escolaridade nesse estudo foi utilizado para analisar o grau de conhecimento formal dos entrevistados. De acordo com a análise dos municípios, a maior frequência de escolaridade dos entrevistados de Capão Bonito e Buri foi o ensino médio completo, com $29 \%$ e $33 \%$ respectivamente (Tabela 1). Dos Santos e Lima (1999) obtiveram resultado semelhante, com $33 \%$ dos entrevistados com ensino médio completo, para Flona de Mário Xavier. No entanto para Flona de Ipanema (SOUZA; MARTOS, 2008) foi registrado uma maior porcentagem de entrevistados com ensino superior.

Com relação a profissão observou-se que em Capão Bonito as duas maiores frequências relativas foram de comerciários e estudantes, que juntos somaram $18 \%$ e, em Buri, a maior frequência relativa foi a categoria estudantes 20\% (Tabela 1). Estes resultados são similares ao obtido por Dos Santos e Lima (1999) em que $27 \%$ dos entrevistados são estudantes, 
porém, diferente dos $30 \%$ dos profissionais liberais apontados por Freitas (2002) em estudo semelhante. A maioria dos entrevistados de Capão Bonito afirmou residir em área urbana (59\%) e a maioria dos entrevistados de Buri (53\%) afirmou residir em área rural (Tabela 1).

Os resultados mostraram que mais da metade dos entrevistados declarou desconhecer o que é uma "Unidade de Conservação", ou seja, 62\% dos entrevistados para Capão Bonito e 64\% para Buri (Tabela 2). Os resultados mostraram ainda que a grande maioria dos entrevistados, em Capão Bonito $82 \%$ e em Buri 78\% (Tabela 2), não conhece a FLONA de Capão Bonito. O resultado do estudo de Moreira e Burns (2015) realizado na FLONA de Tapajós, a qual possui Programa de Uso Público, mostrou que a maioria dos entrevistados (81\%) tinha ciência de que o local utilizado se tratava de uma UC, isso demonstra que a situação encontrada no cenário na FLONA de Capão Bonito pode ser revertida, por meio do Programa de Uso Público, que deverá divulgar a área para comunidade do entorno, e por meio do Programa de Educação Ambiental que deverá conscientizar o público em geral, sobre a existência, importância da Flona e da conservação da Natureza.

Tabela 2: Resumo das respostas referentes ao conhecimento, importância e interesse dos entrevistados em visitar a Floresta Nacional de Capão Bonito, Estado de São Paulo, Brasil.

Table 2: Summary of the responses regarding the knowledge, importance and interest of the interviewees in visiting the Capão Bonito National Forest, State of São Paulo, Brazil.

\begin{tabular}{|c|c|c|c|c|}
\hline Categorias & Capão Bonito & $\begin{array}{c}\text { Total } \\
\%\end{array}$ & Buri & $\begin{array}{c}\text { Total } \\
\%\end{array}$ \\
\hline $\begin{array}{l}\text { Sabe o que é uma Unidade de } \\
\text { Conservação }\end{array}$ & Não & 62 & Não & 64 \\
\hline Tem interesse ou já visitou uma UC & Sim & 54 & Sim & 55 \\
\hline Conhece a FLONA de Capão Bonito & Não & 82 & Não & 78 \\
\hline $\begin{array}{l}\text { Conhece o objetivo da FLONA de } \\
\text { Capão Bonito }\end{array}$ & Não & 97 & Não & 95 \\
\hline $\begin{array}{l}\text { Considera importante a presença da } \\
\text { FLONA em seu município }\end{array}$ & Sim & 94 & Sim & 94 \\
\hline $\begin{array}{l}\text { Tem interesse em visitar a FLONA } \\
\text { de Capão Bonito }\end{array}$ & Sim & 92 & Sim & 93 \\
\hline $\begin{array}{l}\text { Atrativo de maior interesse }-1 \\
\text { Lugar }\end{array}$ & $\begin{array}{l}\text { Caminhada/Tril } \\
\text { ha }\end{array}$ & 39 & $\begin{array}{l}\text { Caminhada/ } \\
\text { Trilha }\end{array}$ & 43 \\
\hline $\begin{array}{l}\text { Atrativo de maior interesse }-2 \text {. } \\
\text { Lugar }\end{array}$ & Cachoeira & 29 & Cachoeira & 25 \\
\hline
\end{tabular}

Além disso, grande parte dos entrevistados (97\% em Capão Bonito e 95\% em Buri), declarou não ter conhecimento sobre o objetivo da FLONA de Capão Bonito (Tabela 2). Dos Santos e Lima (1999) constataram, na FLONA Mario Xavier, que $56 \%$ dos visitantes, desconheciam os objetivos da FLONA, outros 43\%, mostraram leve noção de compreensão dos objetivos.

Apesar de a maioria ter respondido não saber o que é uma Flona, nem conhecer a Flona de Capão Bonito, após serem esclarecidos, a maioria $(94,5 \%)$ afirmou que a presença da Flona na região é importante. Este resultado é semelhante ao apontado por Dos Santos e Lima (1999) em seu 
estudo na FLONA Mario Xavier no qual 99\% dos entrevistados declararam ser importante a presença da UC para o município. Takahashi (2004) salientou que a presença de espaços como as UCs é muito importante numa dada região, pois podem acrescentar à sociedade componentes ambientais e educativos através do uso público e das práticas de Educação Ambiental realizadas nestas áreas.

Da mesma forma, após os esclarecimentos a maioria (92\% em Capão Bonito e 93\% em Buri), interessados em visitar a FLONA de Capão Bonito (Tabela 2). De acordo com Cruz (2017) a interação das pessoas com os espaços naturais contribui com o pensamento crítico e a noção de respeito em relação ao meio ambiente. Para Queiroz (2013), de acordo com seus estudos, não há melhor espaço para a prática à EA do que as UCs, pois essas áreas podem propiciar de fato a interação social in loco com o meio ambiente

Em relação aos atrativos preferenciais dos entrevistados, a grande maioria cita como "caminhada/trilha" como principal interesse (Tabela 2), seguido de "cachoeira". Moreira e Burns (2015) em estudo na FLONA dos Tapajós mostraram em seus resultados que $70 \%$ dos entrevistados participaram de atividades de caminhada nas trilhas. O estudo realizado na FLONA Mario Xavier (Dos Santos e Lima, 1999) mostrou que as principais preferências dos visitantes foram atividades de caminhada e contemplação da natureza 52\%. De acordo com Souza e Martos (2008) dentre as principais motivações citadas pelos entrevistados, para visitar a Flona de Ipanema, foram citadas "contato com a Natureza", "conhecer a Trilha" e "realizar caminhada".

\section{Entrevista com a gestão}

A entrevista com a gestão foi realizada por meio de um roteiro de questões, enviado por e-mail, o qual foi prontamente respondido.

Em relação a importância da Flona para os municípios do entorno a gestão afirmou que a Flona já foi um dos pilares da economia regional, quando realizava o manejo de suas florestas plantadas, mas que naquele momento esta atividade estava paralisada.

Sobre a relação da Flona com os municípios do entorno a gestão afirmou que naquele momento a relação com a população estava um pouco escassa, uma vez que "uma UC de Uso Sustentável sem Plano de Manejo, torna-se bastante estagnada".

A gestão registrou ainda que considerava expressivo o potencial de Uso Público da Flona de Capão Bonito, pois a área apresenta belezas cênicas (vegetação nativa, reflorestamentos, presença de lagos, presença de avifauna) e possibilidade de desenvolvimento de atividades de recreação (ciclismo, acampamento) e Educação Ambiental, afirmando ainda que esta atividade poderia trazer benefícios à comunidade do entorno, aumentando inclusive suas possibilidades de renda. 
Sobre o Plano de Manejo a gestão afirmou que naquele momento o Plano não estava finalizado, mas que em pouco tempo o mesmo deveria ser concluído e publicado.

\section{Análise documental e de atrativos e infraestrutura}

A partir da análise dos Planos de Manejo de UCs da mesma categoria localizadas no Estado de São Paulo ou de UC com Uso Público com localização geográfica próxima a área de estudo, obteve-se uma listagem de itens de infraestrutura e de atrativos naturais presentes na maioria destas UCs. Estes itens foram utilizados para compor a lista de itens presentes nas Tabelas 3 e 4.

A visita na Floresta Nacional de Capão Bonito foi realizada em outubro de 2017, com a intenção de registrar a presença ou a ausência de itens presentes na revisão dos Planos de Manejo das UCs selecionadas para comparação. Os resultados para os itens de infraestrutura estão apresentados na Tabela 3, na qual se pode observar que a FLONA de Capão Bonito possui a maioria dos itens considerados como mínimos para a viabilização do Uso Público. As ausências de audiovisual, bilheteria e lanchonete, Tabela 3, são justificadas pela falta de visitação.

Tabela 3: Infraestrutura relacionada ao Uso Público, existente na Floresta Nacional de Capão Bonito, SP, Brasil.

Table3: Infrastructure related to Public Use, existing in the Capão Bonito National Forest, SP, Brazil.

\begin{tabular}{lcc}
\hline \multicolumn{1}{c}{ Item de infraestrutura } & $\begin{array}{c}\text { No de UCs onde o item } \\
\text { está presente }\end{array}$ & $\begin{array}{c}\text { Presença na FLONA de } \\
\text { Capão Bonito }\end{array}$ \\
\hline Acesso viável & 5 & SIM \\
Alojamento/hospedaria & 6 & SIM \\
Audiovisual & 4 & Sem informação \\
Bilheteria & 5 & NÃO \\
Centro de Visitante & 6 & SIM \\
Escritório & 3 & SIM \\
Estacionamento & 6 & SIM \\
Galpões e Depósito & 3 & SIM \\
Garagem & 5 & SIM \\
Guaritas & 6 & SIM \\
Lanchonete & 3 & NÃO \\
Residências/base & 4 & SIM \\
Sanitários & 6 & SIM \\
Sede Administrativa & 6 & SIM \\
\hline
\end{tabular}


Em relação aos atrativos naturais (Tabela 4) pode-se observar que dentre os 7 atrativos mais comuns existentes nas UCs utilizadas para comparação, 3 estão presentes na FLONA de Capão Bonito. Entre os atrativos naturais que possam vir a ser utilizados em atividades destacamse: os cursos d'água que incluem cinco lagoas, vegetação nativa de Floresta Estacional Semidecidual, além de áreas reflorestadas com "araucária" (Araucaria angustifolia) que é uma espécie nativa originária de Floresta Ombrófila Mista, e de áreas reflorestadas com a espécie exótica (Pinnus spp.). Há também a possibilidade de contemplação da natureza do local, acesso às trilhas, além de observação de elementos da fauna. Atrativos como "Museus" e "Mirante" estão ausentes, mas poderiam vir a ser construídos caso a UC passasse a ser aberta à visitação.

Tabela 4: Atrativos naturais existentes na Floresta Nacional de Capão Bonito, SP, Brasil.

Table 4: Natural attractions existing in Capão Bonito National Forest, SP, Brazil.

\begin{tabular}{lcc}
\hline $\begin{array}{c}\text { Atrativos Naturais e/ou } \\
\text { Histórico/culturais }\end{array}$ & $\begin{array}{c}\text { No de UCs onde o atrativo } \\
\text { está presente (Apêndice } \\
\text { B) }\end{array}$ & $\begin{array}{c}\text { Presença na FLONA de } \\
\text { Capão Bonito }\end{array}$ \\
\hline Cachoeira & 4 & NÃO \\
Caverna & 3 & NÃO \\
Contemplação da Natureza & 6 & SIM \\
Curso d'água (rio, lago) & 5 & SIM \\
Mirante & 3 & NÃO \\
Museu & 4 & NAO \\
Trilha & 6 & SIM \\
\hline
\end{tabular}

A FLONA de Capão Bonito possui ainda atrativos históricos como o "Monumento à Otávio Seppi", soldado paulista morto na área durante a Revolução de 1932, além de uma "Igreja Antiga" localizada na "Vila da FLONA". Estes atrativos podem ser aproveitados, nos roteiros de visitação, além dos atrativos naturais existentes, ampliando assim as possibilidades de interpretação do local.

\section{Discussão Geral}

Belinassi et al (2011) discutem que alguns pontos são importantes e necessários num programa de Uso Público, para que seja de fato estabelecida uma atividade de "ecoturismo". O primeiro ponto seria o máximo de envolvimento da comunidade do entorno com a Unidade de conservação, e o segundo ponto, seria o total empenho da gestão da UC, para que todos cuidados com a abertura da Unidade sejam garantidos. Em seu estudo (BELINASSI et al. 2011) é registraram a importância da gestão envolver e agregar a comunidade no processo de gestão. Neste sentido, os resultados deste estudo apontam um caminho promissor, uma vez que as pessoas do entorno consideram importante a existência da Flona, e tem interesse em visita-la e a gestão considera que o Uso Público pode ser uma forma de aproximar a comunidade do entorno, com possibilidade até mesmo, de geração de renda. 
Maganhoto (2016), ao analisar a FLONA de Irati, observou que os esforços despendidos pela gestão da UC auxiliaram a ampliação dos benefícios trazidos com a utilização pública da FLONA e os resultados se mostraram benéficos, tanto para a própria UC quanto para a comunidade envolvida.

Vale salientar, no entanto, que as atividades de Uso Público, assim como quaisquer usos diretos ou indiretos, podem causar impactos nas áreas naturais onde elas ocorrem. Desta forma, seria fundamental que todos os roteiros e atrativos fossem muito bem planejados, preferencialmente com estudos dos possíveis impactos que a visitação poderia trazer, de modo a se implantar atividades, evitando ao máximo estes impactos ou reduzindo-os a valores mínimos, garantindo assim, a sustentabilidade da atividade de Uso Público na área, como salientado pela gestão e registrado no Plano de Manejo (ICMBIO, 2018).

\section{Conclusões}

Os resultados mostraram que apesar dos entrevistados não saberem, a priori, o significado e o papel de uma Unidade de Conservação, e de não conhecerem a Flona de Capão Bonito, após serem esclarecidos a maioria considerou importante a presença da Flona na região e demonstrou interesse em visitar a área, portanto conclui-se que existe demanda de visitação para a Flona de Capão Bonito.

Os resultados também revelaram que a Flona de Capão Bonito tem atrativos naturais e históricos, que poderiam ser utilizados em roteiros de visitação, e apresenta uma infraestrutura mínima que permitiria abrir a mesma à visitação.

Segundo a visão da gestão da Flona a área apresenta potencial de Uso Público, sendo que esta atividade poderia inclusive contribuir na melhoria da renda das comunidades do entorno. Porém a gestão enfatizou, naquele momento, a importância de ter o Plano de Manejo concluído e publicado, antes da implantação de qualquer a atividade de visitação, pois este é um documento obrigatório que visa nortear todas as ações a serem realizadas na área.

Atualmente (2018) o Plano de Manejo já foi publicado. No zoneamento da área foi prevista uma porcentagem de $0,49 \%$ da área mapeada como "Zona de Uso Público" localizada na região central da Flona, e onde se tem vegetação (reflorestamento) de araucária (Araucaria angustifolia) e eucaliptos (Eucaliptus ssp). Esta zona conta com 2 trilhas e um Centro de Visitantes, sendo permitidas atividades de lazer e recreação, e proibidas atividades como introdução de espécies exóticas e disposição de resíduos em locais inadequados..

O Plano de Manejo incluiu também um Programa de Visitação, Interpretação e Educação Ambiental, que visa promover, orientar e ordenar a atividade de visitação na Flona (ICMBIO, 2018). No entanto, este programa apresentou-se de forma bastante resumida, ocupando apenas duas das duzentas e onze páginas do documento. Este Programa oferece 
apenas diretrizes gerais para as atividades de visitação, não trazendo o detalhamento necessário para a implantação das mesmas.

Sendo assim, o presente estudo pode fornecer subsídios para o detalhamento do Programa de Uso Público, o que de modo algum dispensa a realização de novos estudos, para proposição de roteiros, avaliação da experiência do visitante, e principalmente para avaliação de impactos da visitação.

Acredita-se que com o tempo a Flona de Capão Bonito irá chegar a sua meta ou Visão de Futuro como registrada no Plano de Manejo (ICMBIO, 2018, p.26)

\begin{abstract}
Ser uma Floresta Nacional com vegetação predominantemente nativa, gerar e difundir tecnologias e metodologias para o manejo e uso múltiplo dos recursos florestais nativos e exóticos. Promover a conservação dos recursos hídricos, das espécies nativas da região, garantindo o resgate do material genético florestal estratégico e divulgar sua importância histórica e ambiental, por meio do uso público, buscando reconhecimento social.
\end{abstract}

No entanto, para atingir este objetivo, necessariamente terá que envolver a população do entorno e a sociedade em geral, e para isso o Uso Público poderá se configurar como uma ferramenta estratégica.

\title{
Referências
}

BRASIL, IBDF- INSTITUTO BRASILEIRO DE DESENVOLVIMENTO FLORESTAL. Portaria no 558, de 25 de outubro de 1968. O Parque Florestal do extinto Instituto Nacional do Pinho, sediado em Capão Bonito, Estado de São Paulo, passa a denominar-se Floresta Nacional de Capão Bonito, com as atribuições definidas no $\S 3^{\circ}$, do artigo 15, da Portaria n.․ 141, de 20.02.68. Rio de Janeiro, 25 de outubro de 1968.

BRASIL, SNUC (SISTEMA NACIONAL DE UNIDADES DE CONSERVAÇÃO DA NATUREZA). Lei no 9.985, de 18 de julho de 2000. Institui o Sistema Nacional de Unidades de Conservação da Natureza e dá outras providências. Diário Oficial da União, 23 de outubro de 2002.

BECHARA, F. C. Unidades demonstrativas de restauração ecológica através de técnicas nucleadoras: Floresta Estacional Semidecidual, Cerrado e Restinga. 2006. 248 f. (Tese de Doutorado) - Programa de Pós Graduação de Recursos Florestais - Piracicaba: Escola Superior de Agricultura Luiz de Queiroz, Universidade de São Paulo, 2006.

ICMBIO. INSTITUTO CHICO MENDES DE CONSERVAÇÃO DA BIODIVERSIDADE. PORTARIA № 375, DE 23 DE ABRIL DE 2018. Aprova o Plano de Manejo da Floresta Nacional de Capão Bonito, no Estado de São Paulo (Processo n 02629.000372/2009-21). D.O.U. № 78, terçafeira, 24 de abril de 2018. 
BENSUSAN, N.; A.P. PRATES. (Orgs). A diversidade cabe na Unidades? Áreas protegidas no Brasil. Brasília. IEB. 2014.

BELLINASSI, S.; PAVÃO, A. C.; CARDOSO-LEITE, E. Gestão e Uso Público de Unidades de Conservação: um olhar sobre os desafios e possibilidades. Revista Brasileira de Ecoturismo, São Paulo, v.4, oㅡ 2, p.274-293, 2011.

BUENO, F. P. Educação Ambiental e a visitação em parques: um estudo sobre o Parque Estadual do Morro do Diabo. In: Anais do VIII Congresso Nacional de Ecoturismo e do IV Encontro Interdisciplinar de Ecoturismo em Unidades de Conservação. Revista Brasileira de Ecoturismo, São Paulo, v.4, n.4, p. 520, 2011.

BUSSAB, W. O; MORETTIN, P. A. Estatística básica. São Paulo: Saraiva, 2002.

BRASSIOLO, M. M. Avaliação da regeneração natural de Pinus elliottii Engel. var. elliotti na Floresta Nacional de Capão Bonito, SP. 1988. 112 f. (Dissertação de Mestrado) - Programa de Pós Graduação do Setor de Ciências Agrárias - Universidade Federal do Paraná, 1988. Disponível em < http: www. acervodigital.ufpr.br >

CALDANO, L. T. P. et al. Censo populacional e avaliação da variabilidade genética das populações de mico-leão-preto (Leontopithecus chrysopygus Mikan, 1823) na Floresta Nacional de Capão Bonito-SP. 2014. 62 f. (Dissertação de Mestrado) - Programa de Pós Graduação em Gnética Evolutiva e Biologia Molecular - Universidade Federal de São Carlos, 2014. Disponível em <https://repositorio.ufscar.br/bitstream /handle /ufscar /5542 6107.pdf? sequence $=1$ \&isAllowed $=\mathrm{y}>$.

CAMPOLIM, J. M. Educação Ambiental no desenvolvimento do projeto da trilha pedagógica na floresta nacional de Ipanema. 2016. 61 f. (Dissertação de Mestrado) - Programa de Pós Graduação em Sustentabilidade na Gestão Ambiental - Universidade Federal de São Carlos, Sorocaba, 2016. Disponível em <http://www.ppgsga.ufscar.br /alunos /banco-de-dissertacoes /2016 /DissertaoJackson verso final.pdf>.

COLE, D.; CARLSON, T. Numerical visitor capacity: a guide to its use in wilderness. Gen. Tech. Rep. RMRSGTR247. Fort Collins, CO: U.S. Department of Agriculture, Forest Service, Rocky Mountain Research Station. 2010.

CORNELL, J. Vivências com a Natureza 1. Editora Aquariana. São Paulo. 2005.

CRUZ, S.H.R.; MENDES, F.L.S.; CAMPOS, R.I.R. Ecoturismo e desenvolvimento local na Floresta Nacional de Caxiuanã/Melgaço (PA). Revista Brasileira de Ecoturismo, São Paulo, v.9, oㅡ 6, p.737-750, 2017.

SANTOS, L.A.F.; LIMA, J.P.C. Potencial de Uso Público da Floresta Nacional Mário Xavier em Seropédica, RJ. Floresta e Ambiente, v. 6, no 1, p.23 - 37, jan/dez 1999. 
FREITAS, W. K.; MAGALHÃES, L. M. S.; GUAPYASSÚ, M. S. Potencial de uso público do Parque Nacional da Tijuca. Revista Acta Scientiarum, Maringá, v. 24, no 6, p. 1833-1842, 2002.

IBGE - INSTITUTO BRASILEIRO DE GEOGRAFIA E ESTATÍSTICA -. Manual técnico da vegetação brasileira. Rio de Janeiro: IBGE. 2012.

ICMBIO- INSTITUTO CHICO MENDES PARA CONSERVAÇÃO DA BIODIVERSIDADE. 2009. Roteiro Metodológico para Elaboração de Planos de Manejo de Florestas Nacionais. Brasilia, 2009.

IUCN - THE WORLD CONSERVATION UNION. Guidelines for protected area management categories, 1994. )

LAURANCE, W. F. Conserving the hottest of the hotspots. Biological Conservation, v. 142, nำ 6, p. 1137-1137, 2009.

LEAL, M. S. et al. Caracterização da bacia do córrego Itanguá como suporte à gestão da Floresta Nacional de Capão Bonito/SP visando à conservação da água. 2016. 86 f. (Dissertação de Mestrado) - Programa de Pós Graduação em Planejamento e Uso de Recursos Renováveis Universidade Federal de São Carlos. Disponível em: <https://repositorio.ufscar.br /handle /ufscar /8935>.

MAGANHOTO, R. F.; BAPTISTA, L.; MOREIRA, J. C.; LOHMAN, M. Caracterização e possibilidade de educação ambiental na Floresta Nacional de Irati, Paraná, Brasil. Revista Espacios, v. 37, nº 29, p. 2, 2016.

MALTA. R. R.; COSTA, N. M. C. Gestão do Uso Público em Unidade de Conservação: A visitação no Parque Nacional da Tijuca - RJ. Revista Brasileira de Ecoturismo, São Paulo, v.2, no 3, p.273- 294, 2009.

MATOS, T.P.V. Avaliação da conectividade de remanescentes de vegetação nativa em matriz agrícola, considerando os índices ecológicos para aves. 2015. 58 f. (Dissertação de Mestrado) (Mestrado em Diversidade Biológica e Conservação) - Universidade Federal de São Carlos, Sorocaba, 2015.Disponível em: https://repositorio.ufscar.br/handle/ufscar/8353.

MENDONÇA, R. Educação Ambiental Vivencial. In: FERRADO JR. (Org.). Encontros e caminhos: formação de educadores ambientais e coletivos educadores. Brasília. MMA. 2007.

MITTERMEIER, R. A.; GIL, P. R.; HOFFMAN, M.; PILGRIM, J.; BROOKS, T.; MITTERMEIER, C. G.; LAMOREUX, J.; FONSECA, G. A. B. Hotspots revisited: earth's biologically richest and most endangered terrestrial ecoregions. CEMEX, Sierra Madre, Cidade do México, p. 19-68, 2004.

MYERS, N. et al. Biodiversity hotspots for conservation priorities. Nature, v. 403, n. 6772, p. 853-858, 2000.

MONZ, C. A., COLE, D. N.; MARION, J. L.; LEUNG, Y.F. Sustaining visitor use in protected areas: Future opportunities in recreation ecology research based on the USA experience. Environmental Management, v. 45, p.551562, 2010. 
MOREIRA, J. C.; BURNS, R. Turismo, manejo de uso público e a percepção dos visitantes: coleta de dados na Floresta Nacional do Tapajós (Pará). Universidade Federal de Ponta Grossa, 2015.

NEIMAN, Z. Estudo sobre as motivações para o comportamento próambiente: o potencial transformador do contato com a natureza. Revista Brasileira de Educação Ambiental, v.4, p.206-214, 2009.

QUEIROZ, E. D. Contribuições da Educação Ambiental crítica para o Uso Público sustentável em Unidades de Conservação. In: Anais - Uso Público em Unidades de Conservação, Niterói-RJ, v. 1, № 1, 2013.

RAMOS, M. Disseminação e presença de Pinus elliottii Engelm nas áreas ripárias da Floresta Nacional de Capão Bonito-SP, Brasil. 2015. $104 \mathrm{f}$. (Dissertação de Mestrado) - Programa de Pós Graduação em Recursos Florestais - Universidade de São Paulo, 2015.

RODRIGUEZ, C. Z. Caça legal como forma de controle de uma população invasora de javali na Floresta Nacional de Capão Bonito, São Paulo, Brasil. 2015. 54 f. (Dissertação de Mestrado) - Instituto de Biociências Universidade de São Paulo, 2015.

DOS SANTOS, L.A.F., LIMA, J.P.C. Potencial de uso público da floresta nacional Mário Xavier em Seropédica, RJ. Floresta e Ambiente, v. 6, n. 1, p.23 - 37, jan./dez. 1999.

SÃO PAULO (Estado). Secretaria do Meio Ambiente. Manual de Monitoramento e Gestão dos Impactos da Visitação em Unidades de Conservação. São Paulo, 78 p. 2010.

SOUZA, P. C.; MARTOS, H. L. Estudo do uso público e análise ambiental das trilhas em uma unidade de conservação de uso sustentável: Floresta Nacional de Ipanema, Iperó - SP. Sociedade de Investigações Florestais, Revista Árvore, Viçosa-MG, v.32, № 1, p.91-100, 2008.

TAKAHASHI, L. Uso público em Unidades de Conservação. Cadernos de Conservação, Curitiba, v. 2, № 2, 2004.

TUAN, Yi-Fu. Topofilia: um estudo da percepção, atitudes e valores do meio ambiente. São Paulo: Difel, 1980.

VALENTI, W. M.; GHISLOTI IARED, V. ; DE OLIVEIRA, H. T. Potencial das atividades de uso público do Núcleo Picinguaba do Parque Estadual da Serra do Mar (SP) para uma educação ambiental crítica. Revista Ciência \& Educação (Bauru), v. 21, ํo. 3, p. 709-724, 2015.

\section{Agradecimentos}

Os autores agradecem aos cidadãos de Buri e Capão Bonito e a gestora da Flona Ipanema (Dra. Beatriz de Mello Beisiegel) por terem participado das entrevistas. 
Mariane Thais Santos: Universidade Federal de São Carlos, Sorocaba, SP, Brasil.

E-mail: marianesantos.t@gmail.com

Link para o currículo Lattes: http://lattes.cnpq.br/7263067635074048

Ismail Barra Nova de Melo: Universidade Federal de São Carlos, Sorocaba, SP, Brasil.

E-mail: ismail@ufscar.br

Link para o currículo Lattes: http://lattes.cnpq.br/3576937472687059

Eliana Cardoso-Leite: Universidade Federal de São Carlos, Sorocaba, SP, Brasil.

E-mail: cardosoleite@yahoo.com.br

Link para o currículo Lattes: http://lattes.cnpq.br/2186623269243747

Data de submissão: 21 de novembro de 2018

Data de recebimento de correções: 15 de dezembro de 2018

Data do aceite: 15 de dezembro de 2018

Avaliado anonimamente 


\section{Apêndice I}

Roteiro para entrevista estruturada utilizado com a população do entorno

1)IDADE: anos

2)SEXO:

Feminino ( )Masculino ( )

3)ESCOLARIDADE:

4)PROFISSÃO:

5)VOCÊ RESIDE NO MUNICÍPIO DE CAPÃO BONITO?

Sim ( )Não ( )

6)RESIDE NA ZONA:

Rural ( )Urbana ( )

BAIRRO:

7)RESIDE NO MUNICÍPIO HÁ QUANTO TEMPO?

8)POSSUI FILHOS?

1 a $2($ ) 3 a 4 ( ) Acima de $5($ )

9)FAIXA ETÁRIA:

0 a $6($ ) 7 a $12($ )13 a 18( ) Acima de 18( )

10)COSTUMA REALIZAR PASSEIOS NO MUNICÍPIO?

( ) Naturais

( ) Culturais

( ) Outros

QUAL A FREQUÊNCIA?

11)VOCÊ SABE O QUE É UMA UNIDADE DE CONSERVAÇÃO?

Sim ( )Não ( )

12)JÁ TEVE O INTERESSE DE VISITAR OU JÁ VISITOU UMA UNIDADE DE CONSERVAÇÃO?

Sim ( )Não ( )

13)VOCÊ ACREDITA SER IMPORTANTE A VISITAÇÃO DE UNIDADES DE CONSERVAÇÃO?

Sim ( )Não ( )

14)VOCÊ CONHECE A FLORESTA NACIONAL DE CAPÃO BONITO?

Sim ( )Não ( )

15)VOCÊ SABE QUAL O OBJETIVO DA FLORESTA NACIONAL DE CAPÃO BONITO? Sim ( )Não ( )

16)VOCÊ ACHA IMPORTANTE A FLORESTA NACIONAL DE CAPÃO BONITO PARA MUNICÍPIO?

Sim ( )Não ( )

POR QUÊ?

17)CASO A FLONA CAPAO BONITO ESTIVESSE ABERTA A VISITAÇÃO, VC SE INTERESSARIA EM VISITA-LA?

Sim ( )Não ( )

18) QUAIS ATRATIVOS/ATIVIDADES VOCÊ SE INTERESSARIA EM VISITAR?

( ) Trilha

( ) Visitação de Pico/Mirante

( ) Cachoeira

( ) Caminhada

( ) Visitação de Caverna

( ) Patrimônio Histórico/Cultural

( ) Outros 